\title{
Bringing the Reality to Policymakers
}

\author{
Joy Moncrieffe
}

Abstract Often, researchers assume that disseminating findings to policymakers is straightforward and that policymakers have the best interests of the researched communities at heart. However, this is not necessarily the case in reality. It is useful to remember that while an organisation's principles and objectives can influence attitudes and commitments, policymakers are individuals with multidimensional identities, which are shaped by their social contexts. They are not immune to societies' prejudices. Policymakers can replicate and entrench values that are inimical to those their organisations formally endorse. 'Bringing the reality to policymakers' is rarely a facile and predictable enterprise; instead, it requires that researchers seek to understand policymakers' social contexts and perspectives, the power dynamics within organisations, and among policymakers and the individuals and communities they are meant to serve.

\section{Briefing note}

In the case of our research in Jamaica (Moncrieffe, this IDS Bulletin), the research proposal outlined methodologies for relaying findings to policymakers. On reflection, these were sterile: they made the familiar assumption that persons who claimed to be committed to social change would be open and eager to learn from the data. The methodologies proposed did not include the important preliminary task of seriously researching policymakers' social and cultural frameworks. The proposal did not approach this dimension of the research agenda with the same political sensitivity and rigour that was considered important for working with children and perpetrators of violence. Yet, researchers were soon reminded that policymakers and practitioners can also serve partial interests. They may have responsibility - in some cases, major responsibility - for the structural violence in the inner-cities, including through the interests they have opted to serve and the issues and individuals they have overlooked. They can be intricately involved with maintaining the status quo. Policymakers and practitioners have such substantial diversities among them that researchers who are committed to a social action agenda must be prepared for advocacy, persuasion, intense politics and potential resistance and rejection.

During the research, people who live within Jamaica's inner-cities and many practitioners who are employed to serve them, expressed frustration with the ways in which policymaking and implementation can sustain the social divisions they are meant to reverse. As one respondent explained:

A lot of people keep talking about their aspirations for the country but these aspirations and the way we go about them are influenced by the legacies of class, race and other inequalities that exist.

(From Moncrieffe 2007: 45)

These legacies are reflected in how some policymakers and practitioners approach and work with communities. Respondents told stories of how some agencies have entered certain areas and proceeded to tell people what to do and how to go about change. As they had gained access to the community through organisations that had a long-standing relationship with the residents, there is a perception that relationships between some of the earlier organisations and residents have begun to sour, as residents believe that their trust is being abused. One commented: 'they think that we (the earlier organisations) are simply softening them in order to allow the police and external agencies to come in and dominate them'.

In Jamaica, the scramble for funds has splintered policy implementing agencies, as people try to position themselves in ways that they believe are 
most appealing to donors. Various respondents said that some of these agencies have little knowledge of community realities. Furthermore, there is a tendency to exclude from planning the very people who could inform on realities on the ground:

The government sets up task forces and talks about inner-city development. However, when they are making decisions and planning, they exclude the people from the grassroots. How can the government be looking at inner-city programmes and exclude men like me, when we are the ones who are born and grown, inhale and exhale, eat and sleep in the garrisons? Government needs to capitalise on the experience and expertise we can provide. I do not believe that the government genuinely wants to effect change. It is clear that they want to keep the people - the power balance - in a certain way.

From Moncrieffe 2007: 45)

There were representatives from development agencies who expressed the same opinion. One respondent, a long-standing practitioner, was clear:

Many people who are part of the establishment really do not have a problem with the problems. My feeling is that these problems of violence could have been solved a long time ago.

(From Moncrieffe 2007: 46)

\section{Note}

* This briefing note draws extensively on my 2007 Working Paper, Making and Unmaking the Young 'Shotta' [Shooter]: Boundaries and (Counter)Actions in the 'Garrisons'.

\section{Reference}

Moncrieffe, J. (2007) Making and Unmaking the Young 'Shotta' [Shooter]: Boundaries and (Counter)Actions in the 'Garrisons', IDS Working Paper 297, Brighton: IDS
Throughout the course of the study, researchers came to accept that 'bringing the reality to policymakers' required a carefully crafted, multipronged and long-term strategy. Currently, there are deliberate attempts to publish research findings in people's own voices. Workshops include children and policymakers in order to encourage dialogue between them. The project included a radio programme that allowed children from the inner-cities to air their views publicly and anonymously; that is, from a 'safe space'. The aim was to invite policymakers to speak directly with children, via radio. There are also plans to publish a film that will depict social conditions in the garrisons, including children's perspectives on their social conditionings. The methodologies are evolving.

\section{Conclusion}

This briefing note has underscored that influencing policymakers is neither easy nor predictable, since they often have preconceived ideas of what is appropriate. Furthermore, they may be part of the problem, and may not be interested in knowing about or changing the realities on the ground. Thus, it may be necessary to devise alternative and innovative approaches to influence policymakers in research that incorporates a social change agenda. 